\title{
Design of A Mechanical Agitator for Supplementing Paint Mixing with Standard Facilities
}

\author{
Dr. T. N. Guma, Anthony Agbata \\ Department of Mechanical Engineering \\ Nigerian Defence Academy, \\ Kaduna
}

\begin{abstract}
The paper presents the design of a mechanical agitator for efficiently mixing paint segments to consistent properties in sealed tank of total mass up to $200 \mathrm{Kg}$ without having any contact with the paint itself. Basically, the agitator was designed to consist of a steel supporting frame structure for the tank and a 50mm-diameter-90mm-long steel shaft gear-driven with a torque of $1800 \mathrm{Nm}$ by a $4-\mathrm{Hp}$ electric motor. The agitator's feasible frame configuration and structural specifications were conceptually designed for supporting the paint tank with angle inclination of $22^{\circ}$ in continuous rotation through $360^{\circ}$ during the agitation time. Three square hollow structural steel (SHSS) frame sections of $60 \times 60 \mathrm{~mm}, 50 \times 50 \mathrm{~mm}$, and $40 \times 40 \mathrm{~mm}$ and $3 \mathrm{~mm}$ wall thickness were selected for the structural elements. Operational deflections and stresses in the frame structures were analyzed using effective elasticity formulae with each SHSS section for overall integrity assessment of the agitator in service. The worst case scenario using two $1700 \mathrm{~mm}$-longest structural elements of the frame treated as simply supported with halfweight of the tank uniformly distributed on each was used in the analyses. The analyses indicated a structurally sound design with each SHSS frame section by comparison to acceptable limits for structural deflection and strength code. The agitator can be fabricated by arc-welding the $40 \times 40 \mathrm{~mm}$ SHSS structural elements. The design is recommended to be used to develop the agitator to remove the drudgery of human folk in mix-homogenizing paint in massive tanks to desired consistent properties before blending it with additives in standard facility prior to painting to avoid inconsistencies in the requisite blend properties and consequent paintwork costs.

Key words:- Massive paint tanks, color shed, requisite properties, improper agitation, human drudgery, standard agitators, color blends, paintwork defects, costs.
\end{abstract}

\section{INTRODUCTION}

Proper agitation of paint to obtain its desired consistent properties before painting is an important requirement in industrial and commercial paint applications so as to avoid myriads of costs associated with paintworks. Standard facilities are available for agitating limited quantities of paints in limited sizes of containers. In some plants, paints are acquired and kept in large massive drums or tanks in different colour sheds because of cost and handling advantages in external and internal logistics. The paints are fetched therein the tanks' from the tops and agitatedly mixed with additives in standard facility to obtain the requisite homogeneity and properties for painting. Where the paint is kept fetching in that manner without agitation depending on the daily work need, the paint at the bottom of the tank tends to form sediments so that its properties such as viscosity are not the same with the original paint procured from the supplier. Continued subsequent fetching of such remaining paint for mixing in the facility may not produce the paint with the requisite properties like colour, adhesion, viscosity and flow ability. The paint at the bottom of the tank will therefore require more dilution to obtain specified viscosity at its application temperature. To dilute the paint to obtain the requisite viscosity, solvent is added. Addition of excess or insufficient solvent affects the coloration, gloss, and the film thickness of the paintfinished surfaces after drying. Defects such as; color variation, loss of gloss, and low paint film thickness can therefore be found on painted surfaces if paints are not agitated in such tanks before dispensing them to standard facility for dilution and blending. This typical problem was observed at Peugeot Automobile Nigeria (PAN) Limited factory at Kaduna. Plate 1 was a view of the company's mixing room with drums of 200 to over 500-litre capacity containing paints of various color sheds that needed to be properly agitated each time before any paint fetch from them for blending in standard facility prior to painting. Over the years the company has adopted various methods for agitating paint in such massive tanks before mixing them in the requisite facility. One of the methods involves turning out the whole tank of paint into a large cylindrical impeller type mixing pot to do the initial mixing of the paint without diluting it before transferring to the secondary facility to dilute and carry out final mixing. However there have been a number of problems with such methods, which include;

i. The much labor required to turn out a whole massive tank of paint to be mixed before taking just a small quantity to be diluted for final use and even returning the rest to the drum for storage.

ii. The much number of man hours required to carry out this operation in the pre-mixing operation with many tanks. 
iii. Susceptibility of the paint to lose of fluidity and development of lumps of congealed paint within the container when paints are frequently exposed to atmosphere. This affects the mixing efficiency and quality of the paint stored for future use.

iv. Loss of paint due to the process as some paint must be left in the larger mixing pot each time it is used or pour off.

v. Capital intensiveness as it involves the use of additional equipment such as pumping facility to transfer paint back and front between the storage tank and the primary mixing equipment and final mixing pots in some cases.

These problems have therefore posed challenge to develop a reliable and durable inexpensive agitation means for mixing any segmented paint in massive tanks for use in many small and large plants
The aim of the paper is to present the design a mechanical agitator that can be used to supplement paint mixing with standard facilities where there are mixing shortcomings that results in defects such as undesirable texture, gloss, colour; etc on paintwork finishes. The specific objectives of the work are:

i. To present the design of an agitator that can be capable of mixing paint within its storage tank without having contact with the paint itself to reduce exposure period of the paint to the barest minimum and make it possible to store the paint as desired without any change in its properties and quality even with time to time fetching out of paint portions therein.

ii. To provide a standard solution to a typical problem at PAN Limited plant at Kaduna in Nigeria and pose the innovative idea and ability for solution to similar paint problems elsewhere they exit.

\section{3 Aim and Objectives}

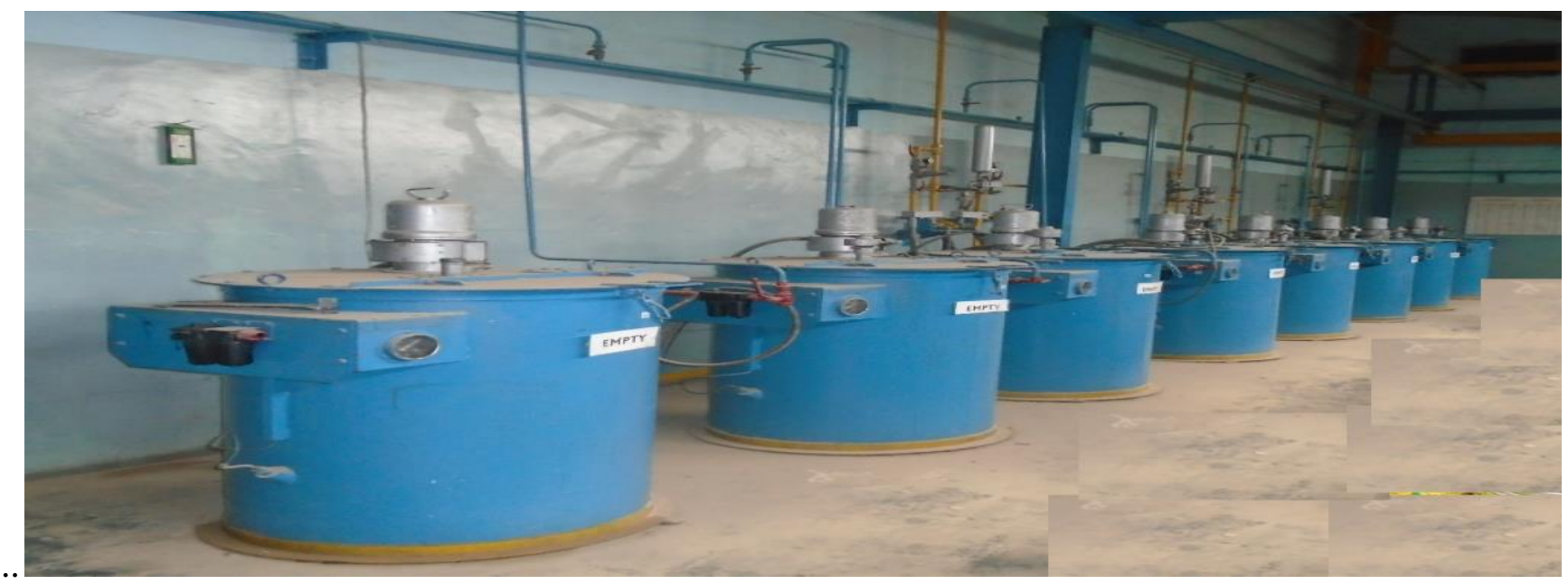

Plate I: Paints as stored in sealed tanks at PAN Limited mixing room

\section{METHODOLOGY}

\subsection{Conceptual Design of the Agitator}

The design was based on specifications of frame structures and configuration for supporting paint tank of $200 \mathrm{Kg}$-mass with angle inclination of $22^{\circ}$ in continuous rotation through $360^{\circ}$ during the agitation time. The feasible frame configuration and structural dimensions of the agitator were conceptually obtained by considering basic parameters such as 500 to $600 \mathrm{~mm}$-diameter tank of height 800 to $1000 \mathrm{~mm}$, and possible size of unidirectional rotating electric motor mountable to the frame for efficiently powering it by direct connection of the motor gear to the shaft of the carriage bed at one end and the other end held in a bearing. A base structure and carriage bed with inclination between $22^{\circ}$ to $45^{\circ}$ and slotted shaft at both ends to be used with a set of belt and anchoring device to secure the tank on the rotary carriage bed were conceived. With such considerations, the configuration was obtained with the basic structural dimensions in centimeters as shown in Fig. 1 and plainly with the tank and electric motor mounted as shown in Fig. 2. 


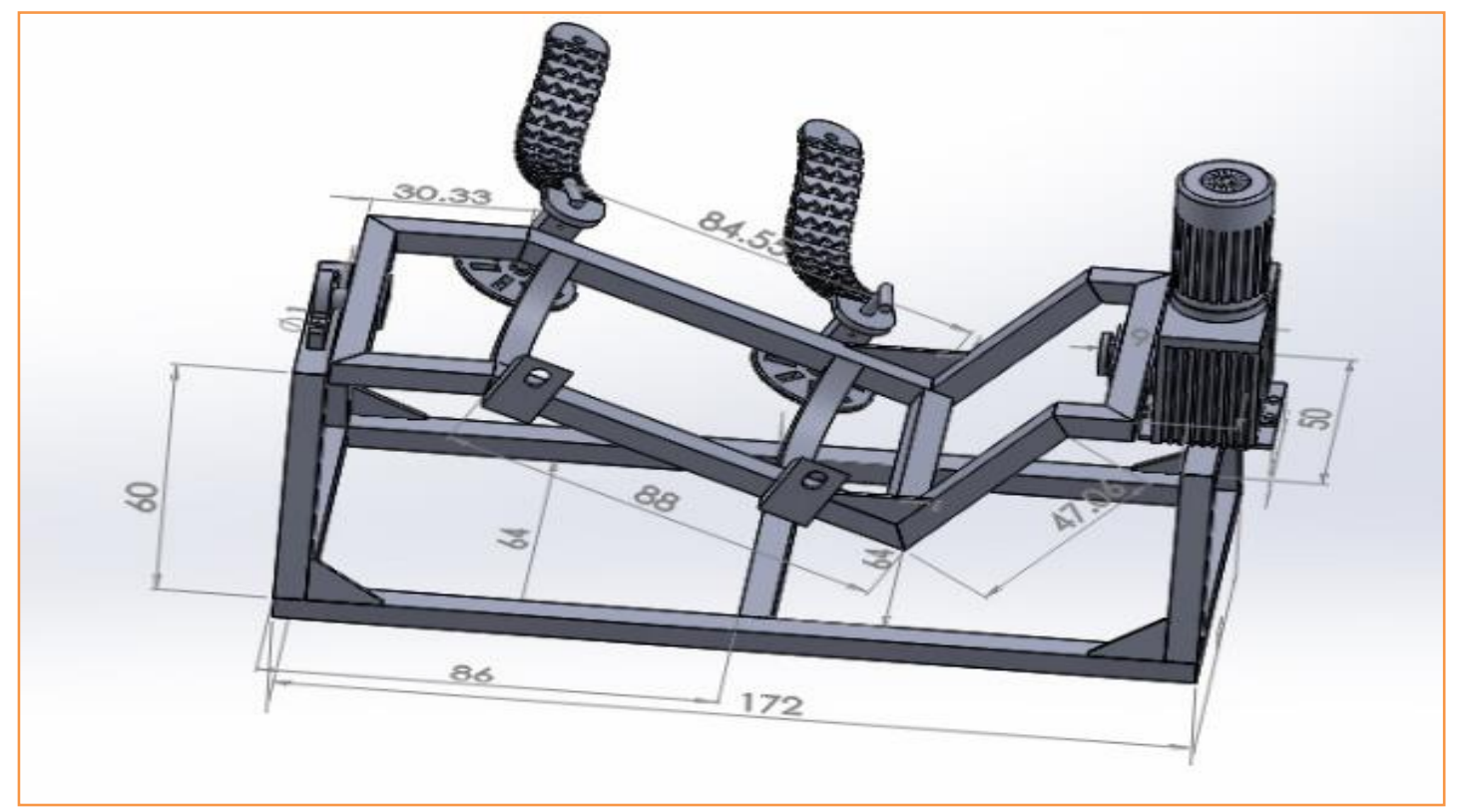

Fig. 1: The conceptualized frame structure of the agitator.

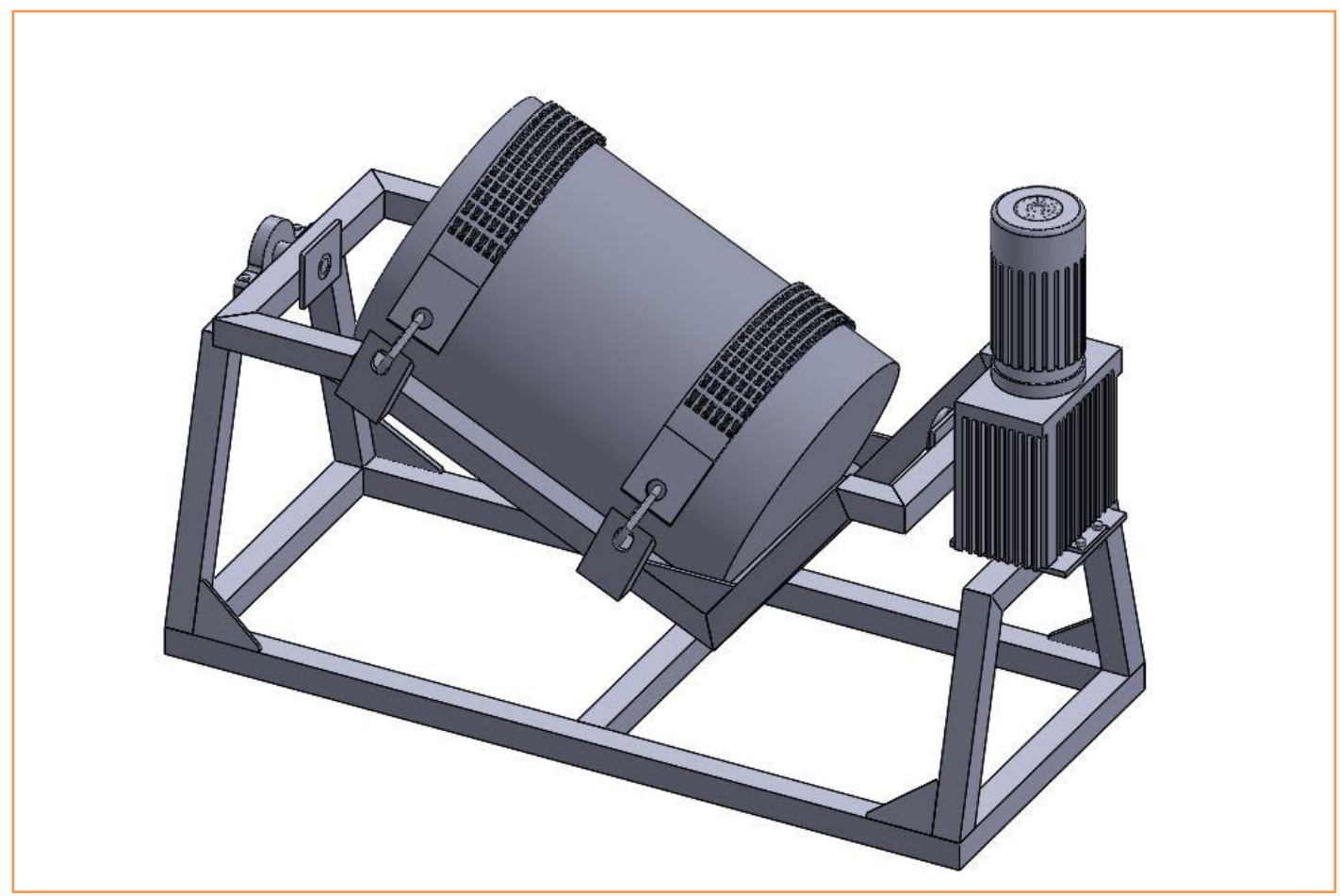

Fig. 2: The conceptualized design of the agitator with the tank in position

\subsection{Design Analysis of Deflections and Stresses in the Agitator Frame Structure with the Tank Weight.}

\subsubsection{Deflections}

Design capacity chart for structural steel hollow sections (SHSS) of sectional profile of a $\mathrm{x}$ a and wall thickness (t) by Austube Ltd [1,2] as shown in Fig.3 was used to select three different SHSS section dimensions of wall thickness $3 \mathrm{~mm}$ for the structural members of the agitator frame as follows.

i. $40 \times 40$ with span of $1750 \mathrm{~mm}$ and weight $1.87 \mathrm{KN}$

ii. $50 \times 50$ with span of $1750 \mathrm{~mm}$ and weight $3.91 \mathrm{KN}$

iii. $60 \times 60 \times$ with span of $1750 \mathrm{~mm}$ and weight $5.95 \mathrm{KN}$ 
Carbon steel was selected as the material make for the frame structure and total load on the agitator frame as $2000 \mathrm{~N}$ due to weight of the tank, and Young's modulus of the steel taken as $200 \mathrm{GPa}[3,4,5]$

According to Austtube Ltd [1], the longer the span of a structural member, the lower its load bearing capacity and the more its deflection with a section profile. Based on these principles the designed longest of the load bearing structural members of the agitator was $170 \mathrm{~cm}(1700 \mathrm{~mm})$ as can be seen from Fig.1. This member was analyzed as the worst-case deflection scenario of the agitator frame with each of the selected SHSS. This was done to check the levels of deflections in the overall frame in each case. In all cases the member was assumed to be simply supported beam with uniformly distributed loading of the tank weight on it as shown in Fig. 4.

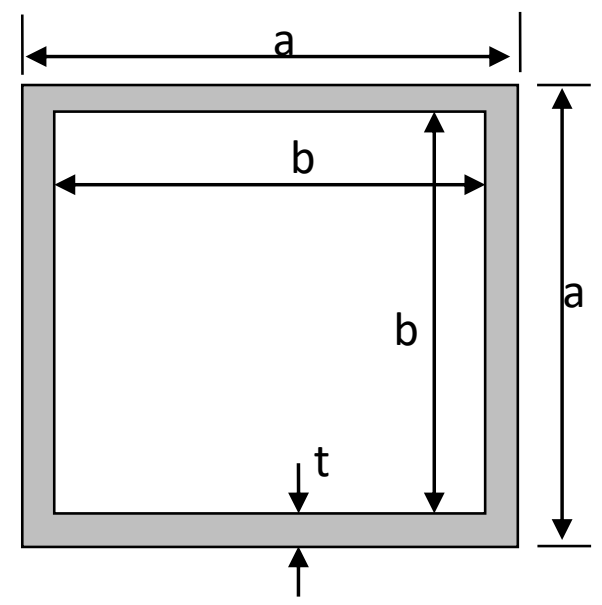

Fig.3: Sectional profile of the square hollow structural steel

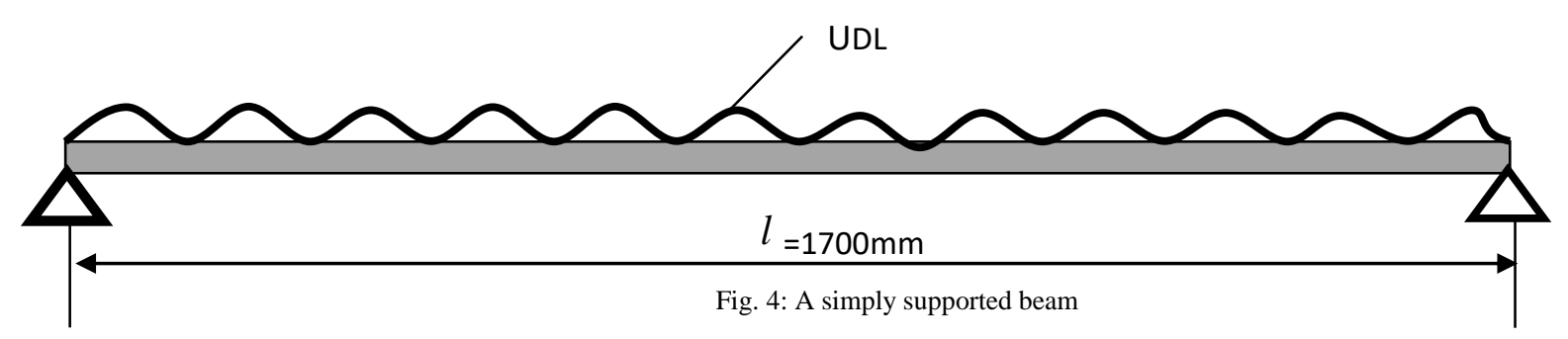

i. Moment of initial (I) of the section in Fig. 3 is given by $[4,5,6]$;

$\mathrm{I}=\frac{a^{4}-b^{4}}{12}$

For the 40x40mm SHSS section,

$$
\mathrm{I}=\frac{40^{4}-34^{4}}{12}=101972 \mathrm{~m}
$$

ii. The maximum deflection $(\delta)$ for the simply supported beam in Fig. 4 with the SHSS is given by $[1,4,5]$ :

$$
\delta=\frac{5 w l^{3}}{384 E I}
$$

Where $\mathrm{w}=1000 \mathrm{~N}$ is half-weight of the tank considering that the tank weight has to be borne by two hollow SHSS sections each of length $\quad(1)=1700 \mathrm{~mm}$ as can be seen from Fig. 1.

$$
\therefore \delta=\frac{(5)(51000)(1700)^{3}}{(384)(200000)(101972)}
$$

\section{$3.14 \mathrm{~mm}$,}

For the 50 by $50 \mathrm{~mm}$ SHSS section,

$$
\begin{aligned}
& I=\frac{50^{4}-44^{4}}{12}=208492 \mathrm{~mm} 4 \\
& \therefore \delta=\frac{(5)(1000)(1700)^{3}}{(384)(200000)(208492)} \\
& \delta=1.53 \mathrm{~mm}
\end{aligned}
$$


For the 60x60 SHSS section,

$$
\begin{aligned}
& \mathrm{I}=\frac{60^{4}-54^{4}}{12}=371412 \mathrm{~m}^{`} \mathrm{~m}^{4} \\
& \therefore \delta=\frac{(5)(1000)(1700)^{3}}{(384)(200000)(371412)} \\
& \delta=0.86 \mathrm{~mm}
\end{aligned}
$$

\subsubsection{Stresses}

The maximum bending stress $\left(\sigma_{b(\max )}\right)$ in the $1700 \mathrm{~mm}$ span element of the agitator with a by a SHSS section carrying a total uniformly distributed load $(\mathrm{w}=1000 \mathrm{~N})$ is given by $[4,5]$;

$\sigma_{b(\max )}=\frac{w L a}{16 I}$

For the 40 by $40 \mathrm{~mm}$ SHSS,

$\sigma_{b(\max )}=\frac{1000(1700)(20)}{16(101972)}=20.84 \mathrm{MPa}$

For the 50 by $50 \mathrm{~mm}$ SHSS,

$\sigma_{b(\max )}=\frac{1000(1700)(20)}{16(208492)}=10.19 \mathrm{MPa}$

For the 60 by $60 \mathrm{~mm}$ SHSS,

$\sigma_{b(\max )}=\frac{1000(1700)(20)}{16(371412)}=5.72 \mathrm{MPa}$

\subsection{Design of the Transmission Shaft}

From the preliminary design drawing of the agitator, radius of rotation $=600 \mathrm{~mm}$, length of shaft $=90 \mathrm{~mm}$, weight of the tank and its content $=2000 \mathrm{~N}$, mass of the rotary assembly $=100 \mathrm{~kg}$ with weight $=981 \mathrm{~N}$, and the overall weight supported by the shaft $=2991 \mathrm{~N}$. The ASME allowable shear stress $=42 \mathrm{MPa}$, ASME allowable normal stress $=84 \mathrm{MPa}[6]$.

i. $\quad$ The applied torque $(T)$ with the vertical force $(f)$ and radius of rotation of the agitator (r) is given by [6]

$$
\begin{aligned}
& T=f y \ldots \ldots \ldots(4) \\
& T=2992 \times 600=1795200 \mathrm{~N}-\mathrm{mm} \\
& T=1795.2 \mathrm{~N}-\mathrm{m}
\end{aligned}
$$

ii. The bending moment $(M)$ with the force $(f)$ acting horizontally on the shaft and horizontal distance $(x)$ between the force and fixed point is given by [6];

$M=f x \ldots \ldots \ldots \ldots(5)$

$M=2992 \times 90=269280 \mathrm{~N}-\mathrm{mm}$

$M=269.28 \mathrm{~N}-\mathrm{m}$

iii. The maximum allowable shear stress $\left(\tau_{\max }\right)$ in the shaft is given by [6];

$\tau_{\max }=\frac{16}{\pi d^{3}}\left[\sqrt{M^{2}+T^{2}}\right]$
With the values of $M$ and $T$ and maximum allowable shear stress of $42 \mathrm{~N} / \mathrm{mm}^{2}$;

$$
\begin{aligned}
\frac{42 \pi d^{3}}{16} & =\sqrt{269280^{2}+1795200^{2}} \\
d & =46.7 \mathrm{~mm}
\end{aligned}
$$

iv. The maximum allowable normal stress $\left(\sigma_{n(\max )}\right)$ in the shaft is given by [6];

v. $\quad \sigma_{n(\max )}=\frac{32}{\pi d^{3}}\left[\frac{1}{2}\left(M+\sqrt{M^{2}+T^{2}}\right)\right]$

Again with the values of $\mathrm{M}$ and $\mathrm{T}$ and maximum allowable normal stress of $112 \mathrm{~N} / \mathrm{mm}^{2}$ for the shaft,

$$
\begin{aligned}
& \frac{112 \pi d^{3}}{32}=\frac{1}{2}\left(269280+\sqrt{269280^{2}+1795200^{2}}\right) \\
& d=45.6 \mathrm{~mm}
\end{aligned}
$$

vi. Taking the larger of the two values the designed shaft diameters, $d=46.7 \mathrm{~mm}$ say $50 \mathrm{~mm}$.

\subsubsection{Design Specification of the Electric Motor to} Drive the Shaft

The maximum operating speed of the agitator was designed to be 60rpm. The torque transmitted by the shaft is the torque to be overcome by the geared electric motor. The relationship between torque, power and speed requirements were used to calculate the size of the electric motor required.

i. $\quad$ Power of the motor $(P)$ is given by [6];

$P=\frac{2 \pi N T}{60}$

Where $P$ is the speed of the motor $=60 \mathrm{rpm}$, and $T$ is the required driving torque of the motor $=$ $1800 \mathrm{Nm}$

$P=\frac{2(\pi)(60)(1800)}{60}=11309.7=11.31 \mathrm{KW}$

\subsubsection{Reduction of power required to drive the agitator.}

The $11.31 \mathrm{Kw}$ power rating required to drive the agitator at 60rpm was seen to be rather very high. However, by using some gear combination the power was reduced to less than $50 \%$ of the calculated value. This was achieved by varying the ratio of the gear teeth between the driver and the driven gears. To do this, a driver gear with 8 numbers of teeth on it to be powered by a $4 \mathrm{Kw}$-electric motor was selected in a general arrangement for speed reduction as shown in Fig. 5. 


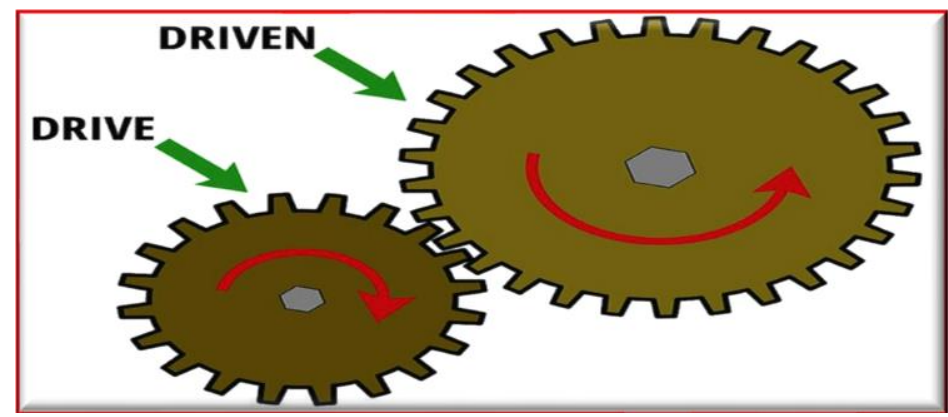

Fig.5: Gear follower arrangement for torque enhancement [7]

Thus, from equation 8 ,

$$
\begin{aligned}
T & =\frac{60 P}{2 \pi N} \\
T & =\frac{(60)(4000)}{2 \pi(60)} \\
T & =636.62 \mathrm{Nm}
\end{aligned}
$$

With the driver having 8 teeth, electric motor power $=$ $4000 \mathrm{w}$, the torque from the electric motor $(T)=636.62 \mathrm{Nm}$ and the required torque to drive the agitator $=1800 \mathrm{Nm}$ the required gear ratio was determined using the following ration relation [7]:

$T=\frac{t}{8}(1800)$

Where $t$ was the number of teeth on the driven gear and $T$ $=636.62 \mathrm{Nm}$. Thus,

$t=\frac{8(636.62)}{1800}$

$t=23$

The required gear ratio was therefore $=8: 23$.
Also, with the required output speed of the driven gear as $60 \mathrm{rpm}$, the speed of the driver $(n)=\frac{23}{8}(60)=174 \mathrm{rpm}$.

Hardened steel was recommended as the material make for the motor gears.

\subsection{Agitator Frame Assembly with the Tank and Parts Identification.}

The component parts of the agitator are identified with number labels as shown in Figs 6, 7, 8 respectively on the assembly with the tank in place, the main subassembly, and base frame units of the agitator which corresponds to the number on the itemized quantity describing the quantity of each part required to build the agitator as shown in Table 1. Fig. 8 shows some exploded views of the various subassembly units of the agitator with details of their parts identification numbers. The paint tank can be loaded in place manually or auto-manually by use of additional equipment such as mobile gantry lift jack equipped with equalizer and chain with an arc shape anchoring device to help anchor the tank.

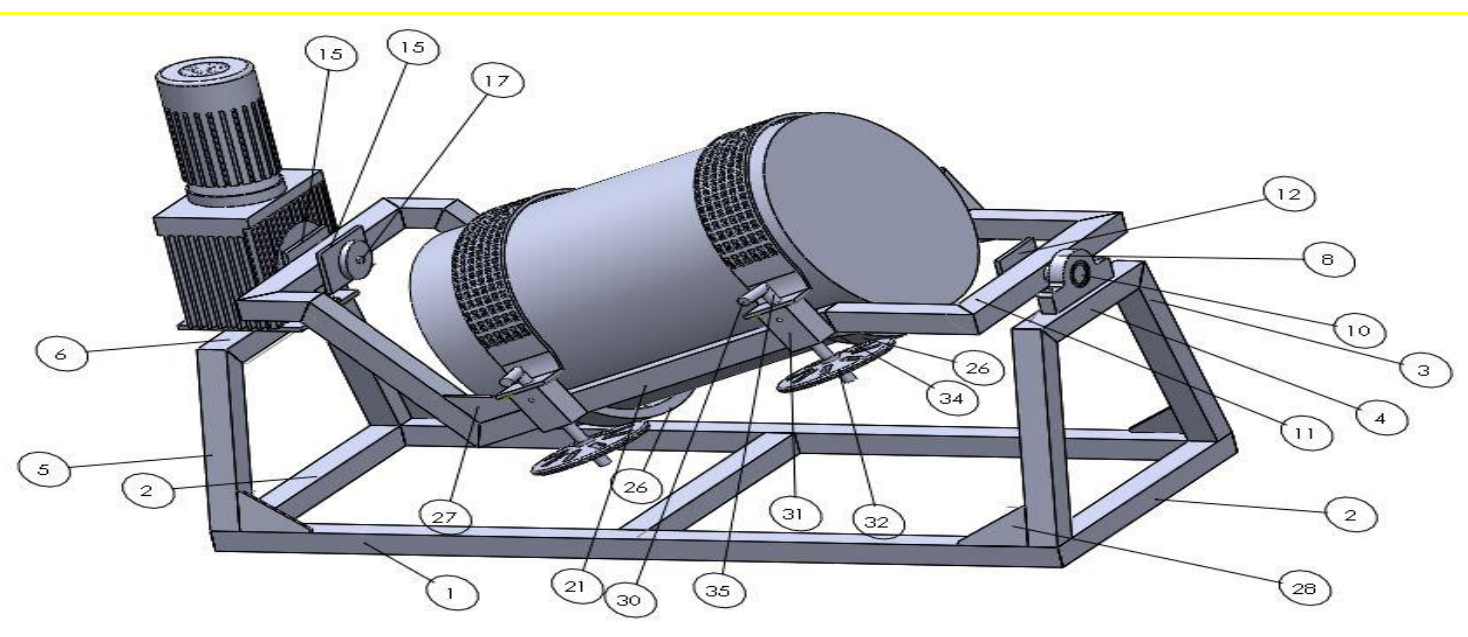

Fig. 6: Part identification numbering on the assembly drawing of the agitator 


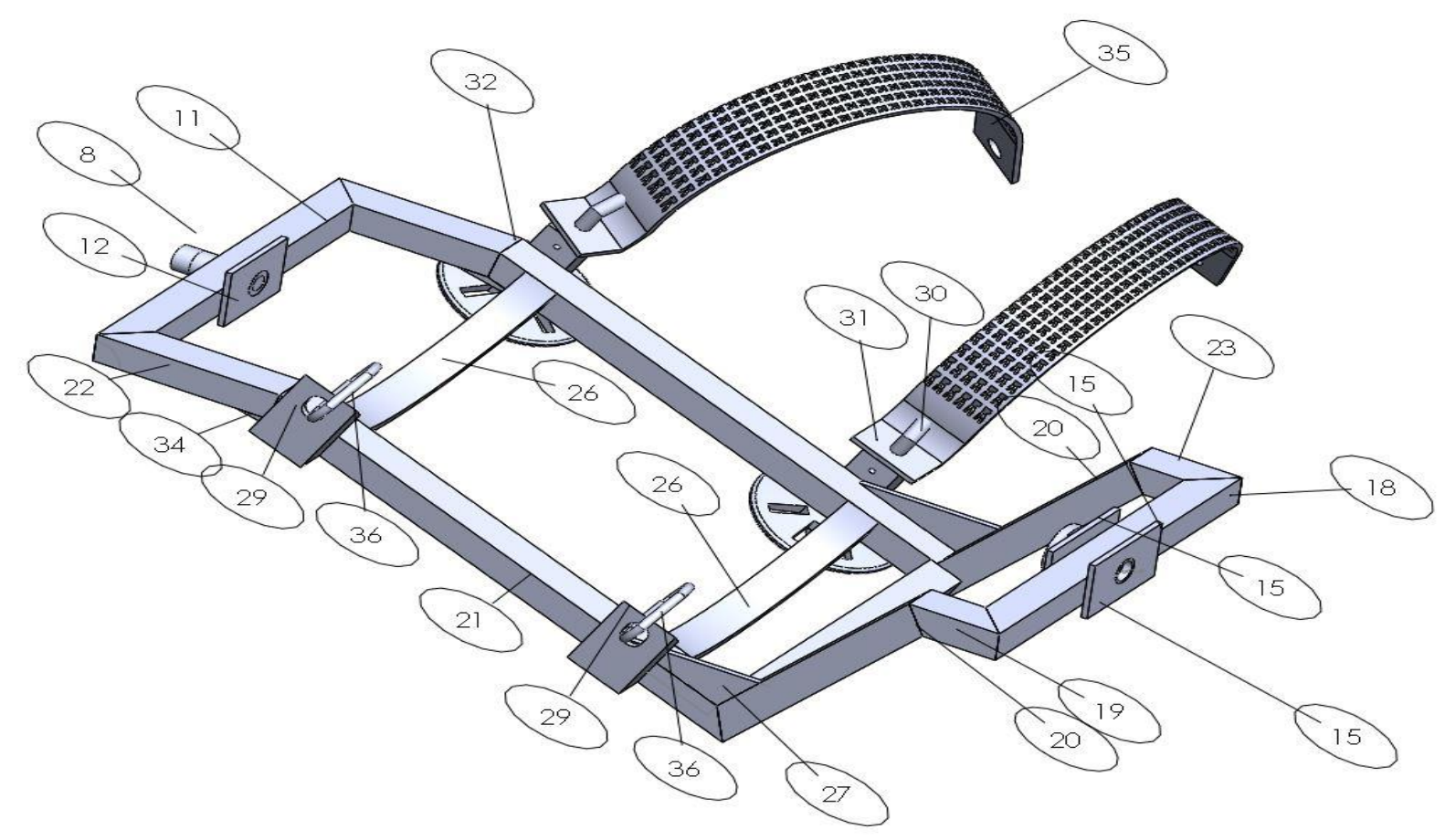

Fig. 7: Part identification numbering on the rotary unit subassembly of the agitator

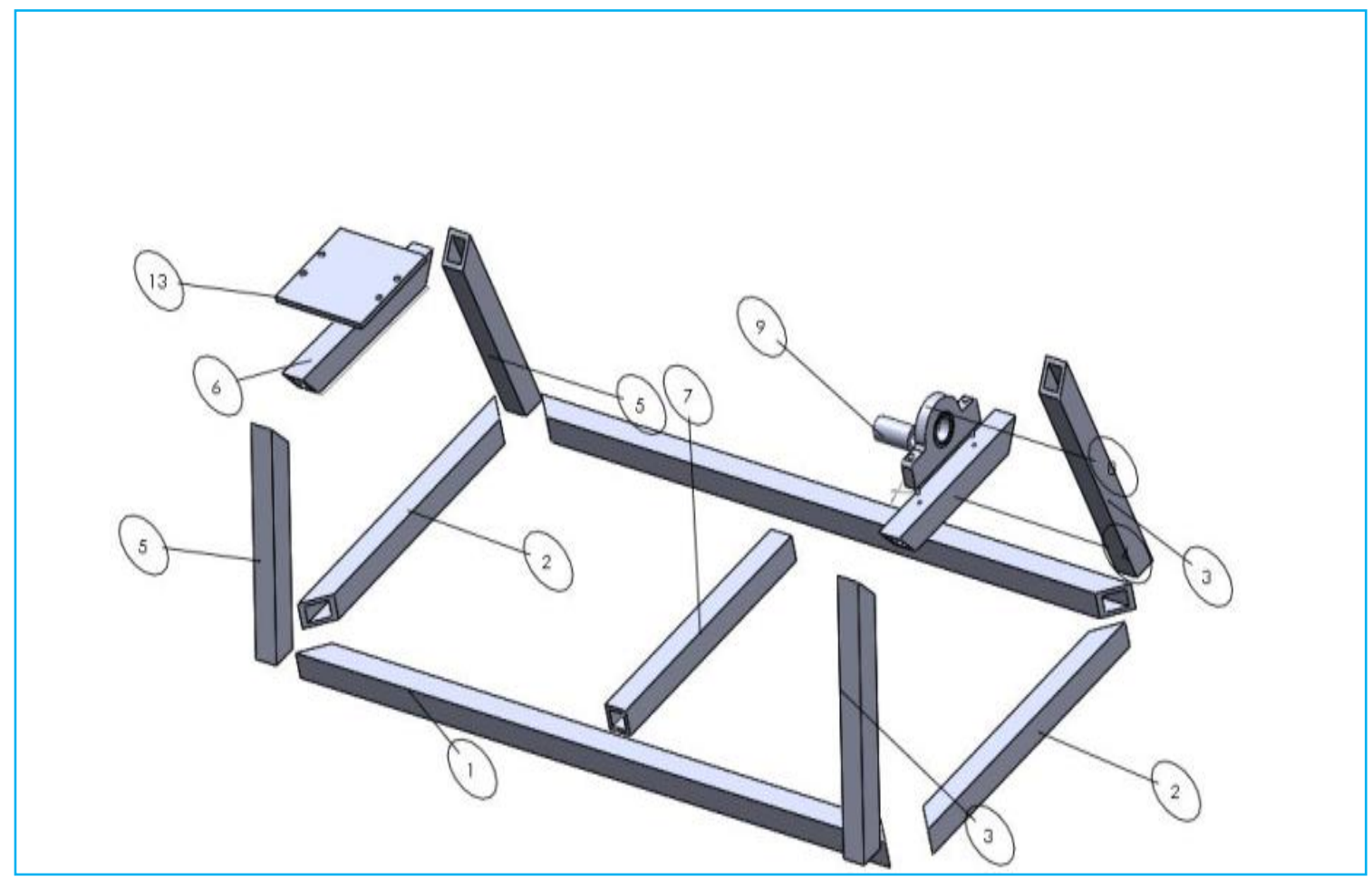




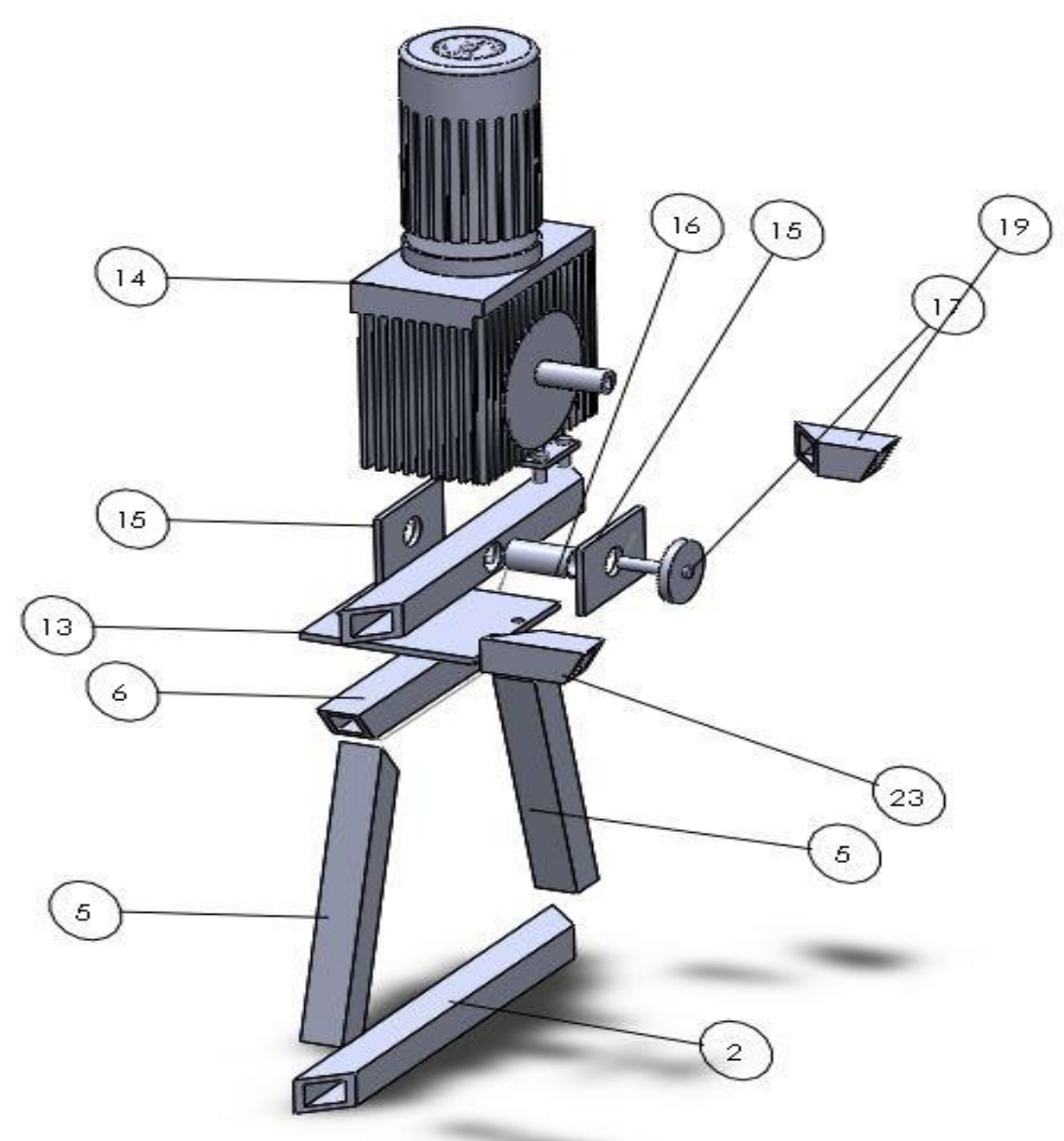

Fig. 8: Some exploded drawings of the agitator.

Table 1: Itemized designed component quantities of the agitator

\begin{tabular}{|l||l|l||l||l||l||}
\hline $\begin{array}{l}\text { Component } \\
\text { No. })\end{array}$ & Description & Quantity & $\begin{array}{l}\text { Component } \\
(\text { No. })\end{array}$ & Description \\
\hline $\mathbf{1}$ & Base long SHSS & 2 & 19 & $\begin{array}{l}\text { R. carrier motor end } \\
\text { shaft holder spacer SHSS }\end{array}$ & 1 \\
\hline \hline $\mathbf{2}$ & Base short SHSS & 2 & 20 & $\begin{array}{l}\text { Rotary carrier vertical } \\
\text { support SHSS }\end{array}$ & 2 \\
\hline $\mathbf{3}$ & Bearing vertical stand SHSS & 2 & 21 & $\begin{array}{l}\text { Rotary carrier base long } \\
\text { SHSS }\end{array}$ & 2 \\
\hline $\mathbf{4}$ & Bearing horizontal base SHSS & 1 & $\begin{array}{l}\text { Rotary carrier base short } \\
\text { SHSS }\end{array}$ & 1 \\
\hline \hline $\mathbf{5}$ & Motor vertical stand SHSS & 2 & $\begin{array}{l}\text { R. C motor end shaft holder } \\
\text { alt. spacer SHSS }\end{array}$ & 1 \\
\hline $\mathbf{6}$ & Motor horizontal base SHSS & 1 & 23 & $\begin{array}{l}\text { Rotary carrier base short alt } \\
\text { SHSS }\end{array}$ & 1 \\
\hline $\mathbf{7}$ & Base long middle braze SHSS & 1 & 24 & Inside metal \\
\hline $\mathbf{8}$ & Bearing & 1 & 25 & R.C. drum holder plate & 2 \\
\hline \hline 9
\end{tabular}




\begin{tabular}{|c|c|c|c|c|c|}
\hline & & & & Plate & \\
\hline 10 & Rotary carrier bearing end shaft & 1 & 28 & $\begin{array}{l}\text { Base long HSS } \\
\text { reinforcement plate }\end{array}$ & 4 \\
\hline 11 & $\begin{array}{l}\text { Rotary carrier bearing } \\
\text { shaft holder SHSS }\end{array}$ & 1 & 29 & $\begin{array}{l}\text { R.C. anchor belt anchor } \\
\text { Plate }\end{array}$ & 2 \\
\hline 12 & $\begin{array}{l}\text { Reinforcement plate } \\
\text { for bearing shaft }\end{array}$ & 2 & 30 & Threaded shaft & 2 \\
\hline$\overline{13}$ & Electric motor base Plate & 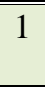 & 31 & $\begin{array}{l}\text { Belt anchor base on the } \\
\text { Steering }\end{array}$ & \\
\hline$\overline{14}$ & Electric motor & $\overline{11}$ & 32 & Lock steering & $\mid 2$ \\
\hline 15 & $\begin{array}{l}\text { Electric motor shaft } \\
\text { holder reinforcement plate }\end{array}$ & 2 & 33 & Drum & 1 \\
\hline 16 & Electric motor shaft hub & & 34 & $\begin{array}{l}\text { R. C. under base } \\
\text { Reinforcement }\end{array}$ & 4 \\
\hline 17 & Shaft lock cover & 2 & 35 & Chain belt & 2 \\
\hline 18 & $\begin{array}{l}\text { Rotary carrier motor end shaft } \\
\text { holder SHSS }\end{array}$ & & 36 & Link & 2 \\
\hline
\end{tabular}

\subsection{Designed operation principles of the agitator}

The basic design principle of operation of the agitator is combination of circular and angular rotation. The agitator is to use the effect of changing position of a rotating tank on its liquid content to increase the turbulence. The principle here is that when you change the position of a continuous rotating drum such that the drum alternates head up and bottom down and head down and bottom up at every $180^{\circ}$ rotation, the liquid (paint) within the container become agitated due to the turbulence that results from the interruption of the direction of flow of the paint caused by abrupt change in position of the container. The agitator is designed to have only one physically moving part which is the carriage bed whose dynamics is intended to agitate the paint in the drum carried by it. As the load bearing surface of the agitator, the carrier is designed to be fitted with a high strength belt and a tightening device for holding paint tank in position to ensure zero play during rotation. The carrier is designed to have extended shaft at both ends to fit into bearings protruding through the bearing at one end to allow for coupling with the powering electric motor. When the electric motor is powered, it turns the carrier through a lateral circular rotation while the liquid container under goes both lateral circular rotation and angular rotation due to the inclined nature of the carrier which ensures that the load remain inclined when held in it. The agitator is designed for simple operation by the electric motor with gear trains running at comparatively low speed and rotating conventionally only in one. When the tank is loaded and firmly secured on the agitator, the equipment can be switched on by pressing the on and off by the off switches. The agitator is designed to continue rotating until complete mixing is achieved at which point the operation is discontinued and the quantity of paint desired extracted and taken to a standard facility for blending with additives, and the paint tank left there or unloaded as desired.

\section{DISCUSSION OF THE DESIGN}

The configuration of the designed agitator frame was seemingly complex so classical design was seen to be tedious and less accurate than conceptual design with theoretical analysis of stresses and deflection for performance assessment of the frame in service. Theoretical analysis of operational deflections and stresses in the designed agitator frame structures due to weight of the paint tank on the frame were evaluated using the longest structural member of length $1700 \mathrm{~mm}$ and three design-selected SHSS sections of $40 \times 40 \mathrm{~mm}, 50 \times 50 \mathrm{~mm}$ and $60 \times 60 \mathrm{~mm}$ of $3 \mathrm{~mm}$ wall thickness as the worst case scenario for deflection and strength as can be seen from sections 2.2.1 and 2.2.2 of this paper. The analyses indicated highest deflection of $3.14 \mathrm{~mm}$ from the $40 \mathrm{x}$ $40 \mathrm{~mm}$ SHSS, $1.53 \mathrm{~mm}$ from the $50 \times 50 \mathrm{~mm}$ SHSS, and $0.86 \mathrm{~mm}$ from the $60 \mathrm{x} 60 \mathrm{~mm}$ SHSS respectively. According to Euro code, deflection due to life load after construction should be limited to Span/500 [8]. Therefore allowable deflection for the $1700 \mathrm{~mm}$-long member $=$ $1700 / 500=3.4 \mathrm{~mm}$. Also according to ACI code, deflection due to life load should be limited Span/360 [8]. Therefore allowable deflection for this member according to the code is $=1700 / 360=4.7 \mathrm{~mm}$. These codes also submitted that designers are at liberty to set their own suitable deflections based on the prevailing conditions with respect to their designed products [8]. In line with these, it is clearly indicative that the agitator frame structures are well designed within acceptable or tolerable limits of deflections. Also the evaluated theoretical stresses in the in the $1700 \mathrm{~mm}$-long member were 20.84, 10.19, and 5.72MPa with the $40 \times 40 \mathrm{~mm}, 50 \times 50 \mathrm{~mm}$ and $60 \times 60 \mathrm{~mm}$ respectively. From these, it was apparent that the operational stresses would be very small compared to the average yield stress of $200 \mathrm{MPa}$ for steel. This also indicated that the agitator frame was designed with high integrity with respect to strength. Compared to other types of joints, welded joints have higher efficiencies. Efficiencies of greater than $95 \%$ are easily possible by welding processes such as arc-welding [9]. This indicates that the stress values of $20.84,10.19$, and $5.72 \mathrm{MPa}$ are equally small compared to the strength of arc-welded carbon steel joints which should be at least say $70 \%$ of the yield strength of carbon steel, that is $140 \mathrm{MPa}$. This 
signifies that if the agitator is fabricated by arc-welding, it will also be equally sound from the standpoint of its operational strength integrity.

\section{CONCLUDING REMARKS}

A mechanical agitator to remove the drudgery of human folk in mixing segmented paint to requisite consistent homogeneity and properties in massive tanks of up to $200 \mathrm{Kg}$ without any contact with the paint has been conceptually designed and presented. A 50mm-diameter$90 \mathrm{~mm}$-length shaft was designed for powering rotational agitation of the tank mounted by a carrier on a designed frame structure through gear-speed reduction of a $4-\mathrm{Hp}$ electric motor with output driving torque of $1800 \mathrm{Nm}$ and tank rotational speed of 60rpm. Operational deflections and stresses of the agitator frame structures were theoretically analyzed with three SHSS sections using practicable elasticity formulae to assess the agitator's integrity in service at the designed rotational speed. The analysis indicated a sound design from the standpoint of structural integrity in service usage of the agitator. The component quantities of the designed agitator have been duly itemized and presented. The design is recommended to be used to develop the agitator for efficiently mix-homogenizing segmented paint in tank to desired consistent properties before blending it with any additives in standard facility prior to painting to avoid inconsistencies in the requisite blend properties and consequent paintwork costs.

\section{REFERENCES}

[1]. Design Capacity Table for Structural Steel Hollow SectionsAUStubeMill Ltd August 2013

[2]. Hollow structural section. http//en.wikipedia.org/wiki/hollow_structural_section. Assessed on 10/5/2018.

[3]. Michael Ashby. Material Selection in Mechanical Engineering Design, $2^{\text {nd }}$ Edn. 1999 Butterworth-Heinemann.

[4]. G. H. Ryder (2003). Strength of Materials. The Macmillan Press Ltd. pp. 56-150

[5]. E.P Popov, Engineering Mechanics of Solids, $2^{\text {nd }}$ ed. Chapter 20, Prentice Hall (Singapore), 1999.

[6]. R. S. Khurmi and J. K. Gupta (2005). A Textbook of Machine. Eurasia Publishing House (PVT) Ltd, pp. 53-86, 509-557.

[7]. Online tsting \& curriculum material-dynamicscience. www.dynamicscience.com.au/tester Assessed on 28/06/2018

[8]. What is the allowable max deflection in a beam, column and slab. Assessed on 13/07/2018.

[9]. Advantages and Disadvantages of Welded Joints over Riveted Joints ME Mechanical Team, Feb 8, 2016. http://memechanicalengineering.com/about-us/ Assessed on 04/08/2018 